\title{
The public acceptance of smallpox vaccination to fight bioterrorism in Japan: results of a large-scale opinion survey in Japan
}

\author{
Hajime Sato $\cdot$ Jun Tomio $\cdot$ Yoshiaki Tanaka $\cdot$ \\ Emiko Iwasaki
}

Received: 3 August 2010/ Accepted: 16 November 2010/Published online: 21 December 2010

(C) The Japanese Society for Hygiene 2010

\begin{abstract}
Objectives This study examines the public acceptance of smallpox vaccinations in the event of a terrorist attack using smallpox. The article also provides public health professionals with the information necessary for such smallpox management.

Methods A questionnaire survey was conducted in a city in Japan asking about prospective action when smallpox vaccination is advised after a terrorist attack and factors that could influence individual decisions about such vaccination. Results Only a tiny fraction of people $(0.12 \%)$ expressed their rejection of vaccination. Of the respondents, $63.6 \%$ showed their intent to be vaccinated promptly when such a measure was required; $28.6 \%$ wanted to decide for themselves, having some reservations. Those in the younger age group, those suffering from hypertension/cardiac diseases, and those who considered the threat of smallpox terrorism less seriously were likely to reserve their vaccination decisions until after examining information.
\end{abstract}

\author{
H. Sato $(\bowtie)$ \\ Department of Public Health, Graduate School of Medicine, \\ The University of Tokyo, \\ Hongo 7-3-1, Bunkyo-ku, Tokyo 113-0033, Japan \\ e-mail: hsato@m.u-tokyo.ac.jp \\ J. Tomio \\ Department of Preventive Medicine, \\ St. Marianne University School of Medicine, \\ Kanagawa, Japan \\ Y. Tanaka \\ Takenotsuka Health Center, Adashi City Government, \\ Tokyo, Japan \\ E. Iwasaki \\ Sendai City Government, Miyagi, Japan
}

Conclusions Communication programs regarding smallpox vaccination should be well planned beforehand and should especially target those people who reserve their decisions at such times. Health professionals should also be well equipped with all information necessary for appropriate and effective smallpox management in the face of such a bioterrorism attack or the strong potential of one.

Keywords Bioterrorism - Smallpox - Vaccination . Countermeasures $\cdot$ Public acceptance

\section{Introduction}

Smallpox, when used as a biological weapon, presents a serious threat to civilian populations [1]. In the case of any bioterrorism attack using smallpox, a set of public health measures, especially the vaccination of high-risk groups, and in some cases even mass vaccination, is critically important to decrease the death toll by containing the spread of the disease [2]. However, implementing smallpox vaccination might encounter some difficulty. Some people would opt out or decline to participate in the vaccination program, threatening the effectiveness of ring vaccination and/or the establishment of herd immunity [3, 4].

Based upon a large-scale community survey, this study examines the public acceptance of smallpox vaccination in Japan, if such a terrorism case/event takes place. Focusing on the people who are reserving their decisions on prophylactic vaccination, their social characteristics are presented. After reviewing the literature on the determinants of personal vaccination decisions, implications of our survey findings are discussed, along with possible communication strategies for effective and efficient smallpox vaccination when warranted in a terrorist attack. 


\section{Materials and methods}

Survey population

The study area is a mid-sized city in the northeast region of Japan (area $19.65 \mathrm{~km}^{2}$ ). Its population is 62,770 (male 31,744 and female 31,026), having a mean age of 38.8 years. The population structure (age, sex) of the residents is similar to that of Japan overall. Proportions of occupations among the residents are also similar to those of the whole country. It was further confirmed by us that the causes of death among city residents were similar to those for the country. From the basic resident register, a total of 2,500 interviewees were selected using stratified random sampling, so that their composition (age and sex) corresponds well to that of the city.

\section{Questionnaire}

A five-item short questionnaire was developed, which asked (1) age, (2) sex, (3) present and past health conditions, including present medications, history of seizure attacks, pregnancy, atopic dermatitis, eczema and other skin diseases, history of smallpox vaccination and its adverse reactions, and history of other vaccine-associated side effects, (4) perceived threat of bioterrorism using smallpox (Can such terrorism take place?), and (5) the prospective action if a smallpox terrorist attack were to take place (anywhere in the world) and a smallpox vaccination were to become necessary (in Japan). Questionnaire sheets were handed directly to the interviewees by public health workers and, after a week, were collected in person by the workers. Interviewees were advised to ask the assistance of family members or public health workers if they felt any difficulty in answering the questions. The collection rate was $77.6 \%$. The rate of valid response (fully answered all questions) was $67.0 \%$.

\section{Statistical analysis}

This study examined the responses from those $\geq 18$ years of age, since the responses from the younger population were considered unreliable because of having many unanswered items. A total of 1,675 responses were retained for analysis. The ages were grouped into three categories: 18-29 years old, 30-64 years old, and older than 64. These age groups have a different history of smallpox vaccination and occupational status. People from the first group have never received any smallpox vaccination. Those in the second and third groups were vaccinated in their childhood. While people in the second group are mostly still working, most of those in the third group were considered to be retired.
According to the answers to the question about a prospective action (item 5 ), the respondents were classified into two groups, namely, the independent thinker group (Decide for myself after collecting and examining information or Decide for myself after consulting with trustful physicians) and the others [Desire a vaccination as soon as possible; Obey orders from local governments and public health centers; Decline a vaccination in any situation; or Do not know (how to make such a decision)]. The former group was considered to be comprised of those people who manifested their information needs and should especially require effective communications programs for mobilization.

First, the descriptive statistics of the demographic basics and those of the responses to the study questions were obtained. Then, a bivariate association of the response to each question with a prospective action (the independent thinker group) was tested. Finally, a multiple logistic regression analysis was performed to find out which factor independently predicted an individual to be in the independent thinker group. All of the variables used for these bivariate tests, except for pregnancy and past side effects from smallpox vaccination, were included in the model as explanatory (independent) variables.

\section{Ethical approval and informed consent}

The study was reviewed and approved by the Research Ethics Review Board of the Sendai City Government and that of the Sendai Quarantine Office, the Ministry of Health, Labor, and Welfare. The purposes of this study were explained on the cover letter of the questionnaire. Only the subjects who agreed with these purposes were requested to answer and return the questionnaires.

\section{Results}

Summary statistics for the study subjects are presented in Table 1, including age group distribution and sex. The mean and standard deviation of the subjects' ages were $52.2 \pm 18.6$ years. Of the group, $37 \%$ had a known history of vaccination for smallpox in their childhood, $0.7 \%$ of whom remembered they had side effects from the vaccination. Concerning the conditions amenable to the possible side effects of smallpox vaccination, 20\% reported either past or present dermatologic disorders (including atopic dermatitis); 3\% had immunologic disorders; $4 \%$ had experienced seizure attacks. While $16 \%$ of the people suffered from hypertension or cardiac disease, only $0.8 \%$ of the women were pregnant. The majority $(77 \%)$ of the people responded that they did not know about the future threat of bioterrorism using smallpox. Only 17\% considered that there was such a threat. 
Table 1 Subject descriptions

\begin{tabular}{ll}
\hline Subject descriptions & $n(\%)$ \\
\hline Age groups (ages) & $278(16.6)$ \\
$18-29$ & $915(54.6)$ \\
$30-64$ & $482(28.8)$ \\
$65-$ (years old) & $895(53.4)$ \\
Gender (female) & \\
Risk factors for vaccination side effects & $338(20.2)$ \\
Dermatologic disorders (past and present) & $47(2.8)$ \\
Immunologic disorders & $58(3.5)$ \\
History of seizure attacks & $267(15.9)$ \\
Hypertension/cardiac diseases & $7(0.78)^{\mathrm{a}}$ \\
Pregnancy (present) & $27(1.6)$ \\
Past side effects from vaccinations & $7(1.1)^{\mathrm{b}}$ \\
not for smallpox & $610(36.4)^{\mathrm{c}}$ \\
Past side effects from smallpox vaccination & $288(17.2)^{\mathrm{c}}$ \\
Past smallpox vaccination (yes) & \\
Serious threat perception of bioterrorism & Total $n=1675$ \\
from smallpox (yes) & \\
\hline a Proportion among females & \\
b Proportion among those with past smallpox vaccination \\
c No includes "Do not know"
\end{tabular}

Table 2 Prospective actions for smallpox vaccination

\begin{tabular}{lr}
\hline Prospective actions & $n(\%)$ \\
\hline Action 1: Desire a vaccination as soon as possible & $475(28.4)$ \\
$\quad \begin{array}{l}\text { Action 2: Decide for myself after } \\
\quad \text { collecting and examining information }\end{array}$ & $196(11.7)$ \\
$\quad \begin{array}{l}\text { Action 3: Decide for myself after consulting } \\
\quad \text { with trusted physician }\end{array}$ & $283(16.9)$ \\
$\quad$ Action 4: Obey orders from local & $590(35.2)$ \\
$\quad$ government and pubic health center & $2(0.12)$ \\
Action 5: Decline a vaccination in any situation & $129(7.70)$ \\
$\quad$ Action 6: Do not know (how to decide) & $479(28.6)$ \\
Independent thinkers (actions 2 and 3) & $1196(71.4)$ \\
Others (actions 1, 4, 5, 6)
\end{tabular}

Asked about a prospective action if a smallpox vaccination were to become necessary under the threat or the incidence of bioterrorism, $64 \%$ were apt to receive prompt vaccination; $35 \%$ expressed that they would act in accordance with the orders from local their government or public health center; $28 \%$ desired immediate vaccinations (Table 2). Only 2 out of $1,675(0.12 \%)$ expressed that they would decline a vaccination under all circumstances. On the other hand, $17 \%$ of respondents answered that they would decide on such vaccination after consulting with a trusted (family) physician, and $12 \%$ would make up their minds for themselves after examining the information then available. Those two groups of people (39\%) were regarded as independent thinkers.

An examination of the bivariate associations disclosed the following (Table 3). The independent thinker group was comprised significantly more of younger people. On the other hand, this (independent thinker) group had a smaller proportion of people who considered the threat of smallpox bioterrorism to be real. Concerning the other factors, e.g., the history of past smallpox vaccination, there was no statistically significant difference observed between the two groups (the independent thinker group versus the other).

The results of a multiple logistic regression analysis confirmed that the factors, listed above as being bivariately associated, were the independent predictors of independent thinkers (Table 4). Belonging to the middle or older age groups (OR 0.712 and 0.630, respectively, compared to the younger age group) and a serious consideration of smallpox bioterrorism (OR 0.629) increased the likelihood that a person would be an independent thinker. Change of reference age group in the model disclosed that there was no statistically significant difference in the likelihood that a person would be an independent thinker between two conditions, belonging to the middle age group (30-64 years) or to the older age group ( $\geq 65$ years). Furthermore, it was disclosed that suffering from hypertension and/or cardiac diseases decreased the likelihood of being an independent thinker (OR 1.474).

Inclusion and exclusion of two factors, i.e., pregnancy and past side effects from smallpox vaccination, also did not significantly change the results of logistic regression analyses.

\section{Discussion}

Vaccination against smallpox used in bioterrorism

Core components of the public health management of a terrorism attack using smallpox would be: vaccination (ring vaccination and mass vaccination), adverse event monitoring, confirmed and suspected smallpox case management, contact management, identifying, tracing and monitoring contacts, and quarantine. Here, smallpox vaccination strategies would encompass a set of vaccination programs [5]. Pre-event (pre-exposure) vaccination includes: (1) selective pre-exposure vaccination: vaccinating high-risk subpopulations before the known release of the smallpox virus or the occurrence of any smallpox cases; (2) mass pre-exposure vaccination: vaccinating an entire population before the occurrence of any smallpox cases or other known release of smallpox virus. Post-event (after exposure) vaccination 
Table 3 Possible factors associated with prospective/potential actions

\begin{tabular}{|c|c|c|c|}
\hline & $\begin{array}{l}\text { Independent thinkers }(n=479) \\
n(\%)\end{array}$ & $\begin{array}{l}\text { Others }(n=1196) \\
n(\%)\end{array}$ & $\begin{array}{l}\text { Difference } \\
p \text { value }\end{array}$ \\
\hline \multicolumn{4}{|l|}{ Age group } \\
\hline $18-29$ & 99 (20.7) & $179(15.0)$ & \multirow[t]{3}{*}{0.020} \\
\hline $30-64$ & $250(52.2)$ & $665(55.6)$ & \\
\hline $65-$ & $130(27.1)$ & $352(29.4)$ & \\
\hline Gender (female) & $257(53.7)$ & $638(53.3)$ & 0.914 \\
\hline \multicolumn{4}{|l|}{ Risk factors for vaccination side effects } \\
\hline Dermatologic disorders (past + present) & $107(28.6)$ & $231(19.3)$ & 0.164 \\
\hline Immunologic disorders & $15(3.1)$ & $32(2.7)$ & 0.610 \\
\hline History of seizure attacks & $19(4.0)$ & $39(3.3)$ & 0.475 \\
\hline Hypertension/cardiac disease & $88(18.4)$ & $179(15.0)$ & 0.085 \\
\hline Pregnancy (present) ${ }^{\mathrm{a}}$ & $4(1.6)$ & $3(0.47)$ & 0.090 \\
\hline Side effects from other vaccinations & $9(1.9)$ & $18(1.5)$ & 0.583 \\
\hline Side effects from smallpox vaccination ${ }^{\mathrm{b}}$ & $3(1.9)$ & $4(0.88)$ & 0.381 \\
\hline Past smallpox vaccination (yes) ${ }^{\mathrm{c}}$ & $157(37.9)$ & $453(32.8)$ & 0.056 \\
\hline Sense of serious threat of bioterrorism from smallpox (yes) ${ }^{\mathrm{c}}$ & $62(12.9)$ & $226(18.9)$ & 0.004 \\
\hline
\end{tabular}

$p$ values for difference were calculated by $\chi^{2}$ test or Fisher's exact test

${ }^{\text {a }}$ Proportion among females

${ }^{\mathrm{b}}$ Proportion among those with past smallpox vaccination

c No includes "Do not know"

Table 4 Predictive factors of independent thinkers

\begin{tabular}{lll}
\hline & Odds ratio & $p$ value \\
\hline Age group & & \\
18-29/30-64 & 0.712 & 0.029 \\
18-29/65- & 0.630 & 0.013 \\
Gender (female) & 1.009 & 0.935 \\
Risk factors for vaccination side effects & & \\
$\quad$ Dermatologic disorders (past + present) & 1.165 & 0.277 \\
Immunologic disorders & 1.245 & 0.502 \\
History of seizure attacks & 1.211 & 0.513 \\
Hypertension/cardiac diseases & 1.474 & 0.013 \\
Side effects from other vaccinations & 1.192 & 0.675 \\
Past smallpox vaccination (yes) & 0.861 & 0.212 \\
Serious threat from smallpox bioterrorism (yes) & 0.629 & 0.003 \\
\hline
\end{tabular}

Results of multiple logistic regression analysis with all the variables listed in Table 3, except pregnancy and past side effects from smallpox vaccination, as explanatory (independent) variables. Model $p=0.003$

a No includes "Do not know"

includes: (1) containment vaccination (ring vaccination): vaccinating contacts of known smallpox cases, accompanied by vaccination of their potential contacts in anticipation of the original contact's becoming ill; (2) mass post-release vaccination: vaccinating an entire population after the occurrence of a smallpox case or other documented release of smallpox virus.

Vaccination, when warranted, should be given within a certain period of time. Transmission of the smallpox virus occurs after onset of the rash. The patient is most infectious from onset of rash through the first 7-10 days of the rash $[6,7]$. For the post-event vaccination to be effective, vaccination should be administered within 4 days after exposure to lessen the severity of, or even prevent, the illness [8].

In light of the possible adverse side effects, there are certain groups for whom elective vaccination is not recommended because of the greater risk of complications. Smallpox vaccination is contraindicated for the following groups of people in Japan: those (1) known to have anaphylaxis with vaccines; (2) presenting manifest pyrexia; (3) suffering from serious acute diseases; (4) with immunologic disorders or receiving immunosuppressive treatments; (5) pregnant; (6) with dermatologic diseases (e.g., past and present skin eczema, atopic dermatitis, burns, pustular rash, chickenpox, and herpes zoster); and (7) having certain other conditions (past and present encephalitis; cardiovascular diseases such as coronary heart diseases, congestive heart failure, cardiomyopathies, and exertional dyspnea). Those who have more than three conditions of hypertension, hypercholesteremia, hyperglycemia or diabetes mellitus, familial history of heart disease, and current smoking also should not be vaccinated [9]. 


\section{Known factors affecting vaccination decisions}

In general, the main deciding factor for voluntary vaccination is the risk of disease exposure and negative outcomes versus the benefits and risk of vaccination (vaccine effectiveness vis-a-vis individual vulnerability and concern about side effects). This corresponds with the theory of rational action that people weigh the possible benefits of an action (in this case, the protection gained from vaccination) against its costs (including the risk of incurring damages from the side effects of vaccination) [10]. Any perceived low ratio of personal benefits compared to adverse effects results in non-vaccination decisions [11].

According to the past studies on adult vaccination behaviors (influenza, anthrax, pneumococcal vaccination), factors associated with the increased likelihood of vaccination are the belief that a vaccine is effective in preventing the disease (prevention of sickness absence and the prevention of disease spread) [12]; the belief that side effects of vaccination are uncommon and/or mild [13]; the perception of high vulnerability to the disease; [14], past vaccination experience [15, 16]; older age [17]; provider (physician) recommendation [18, 19]; awareness (and attention paid to media news) of vaccination [20]; and ethnicity [21, 22]. On the other hand, the most common primary demotivators are concern about safety and efficacy [23, 24]. A perceived low likelihood of contracting the disease, cost concerns, and lack of time to obtain the vaccination lead to a rejection of the vaccination [12]. More recent reports on individual decisions for vaccination against $\mathrm{H} 5 \mathrm{~N} 1$ and $\mathrm{H} 1 \mathrm{~N} 1$ influenza confirm that those factors work as major determinants [2527]. It should be noted, however, that the presence of chronic diseases does not always determine the individual perception of vulnerability, thus not necessarily motivating vaccination [28, 29].

Consistent with those studies cited above, any individual decision about smallpox vaccination, as has been thus far reported, is affected by a set of factors. According to studies by the US National Smallpox Vaccination Program, factors independently associated with vaccination include previous smallpox vaccination, having little or no concern about vaccine adverse events, gender (male), ethnicity, a policy to reimburse for travel or other out-of-pocket compensation, and a high chance of compensation if adverse events do occur. Self-assessed knowledge of smallpox vaccination and a previous history of smallpox vaccination were also positive predictors of vaccination [30, 31]. On the other hand, the leading reasons for non-vaccination were concern about side effects [32], the belief that the risk of outbreak (smallpox attack, and exposure to it) was not high [33], concern about personal contraindications or in household contacts, and concerns about transmission to household contacts [34, 35]. Thus, among those not willing to undergo vaccination, concern about adverse events and the risk of vaccination outweighing vaccination benefits were leading reasons for not being willing to be vaccinated [36].

Public attitudes on smallpox vaccination in Japan

The results of our survey indicate that the majority (more than $60 \%$ ) of the people in Japan are willing to receive smallpox vaccination promptly if terrorism should occur using smallpox any place in the world, and only a tiny fraction would refuse to do so. However, a substantial portion $(29 \%)$ would reserve their decision until they obtained sufficient information or consulted with their physicians (independent thinkers). Younger people, those suffering from hypertension or cardiac diseases, and those who do not consider the threat of smallpox bioterrorism to be serious are likely to be independent thinkers. Those factors, found to be predictive of being independent thinkers, are more or less consistent with the findings reported before in other countries.

Younger people, mostly healthy, generally have a small sense of vulnerability and a greater sense of self-efficacy, which can lead them to be dubious about the necessity and/ or effectiveness of smallpox vaccination, and further to decide on vaccination for themselves [37]. They are also a group of people who have better access to health information, which also induces them to be independent thinkers, not showing blind deference to authority (government instructions) [38].

It was also disclosed that those who do not consider the threat of bioterrorism using smallpox to be serious are more likely to be independent thinkers, reserving their decisions, than those who consider that threat to be real. This finding is consistent with the observation in the United States, which indicated that people become more willing to be vaccinated when a smallpox case appears (geographically) closer to them [39]. It could be the case that people become less likely to be independent thinkers when a bioterrorism threat is perceived to be real.

Our survey results suggest that those for whom the smallpox vaccination is contraindicated do not necessarily fall into the independent thinker group, and, therefore, they are not always cautious about the vaccination, recognizing its risks that are particular to them: Only those suffering from hypertension or cardiac diseases are more likely to be so. This relationship became evident only after controlling for the confounding effects of the other factors, such as age. Older people more commonly suffer from hypertension or cardiac diseases and, at the same time, are less likely to be independent thinkers.

For those people to be prudent in receiving vaccination, they should be concerned about their vulnerability, which 
may be greater than the vulnerability of healthy people, such as the susceptibility to (and outcomes of) smallpox and the amenability to treatment of vaccine side effects. When the latter exceeds the former, assuming that the other conditions are equal, people might be more wary about vaccination [40]. It has been reported that people do not always consider themselves to be in a high-risk status for contracting the disease, nor do they regard themselves as being amenable to the side effects of vaccination, as indicated by medical expertise [41]. Psycho-behavioral mechanisms of vaccination decisions still need to be examined further in Japan.

On the other hand, a past history of smallpox vaccination was found not to be a predictor of being an independent thinker. Our analysis disclosed that people with a history of smallpox vaccination are more likely to get vaccinated without further considerations (choosing the following prospective actions: desire a vaccination as soon as possible or obey orders from local governments and public health centers). The relationship was found to be statistically significant both by the bivariate testing (chisquare test) and by the multivariate analysis (multiple logistic regression analysis with these actions being the dependent variable). This confirmed the finding (status quo bias) of a preceding study that previous vaccination affects the decision to be vaccinated in the future [42].

\section{Crisis communication for effective smallpox vaccination}

Although it was not examined in our survey, fear of side effects was reportedly the most common reason for nonvaccination. Perception of risk, however, does not always correspond to actual risk. Many of the group who were unwilling to be vaccinated reportedly overestimated the risk of severe adverse reactions [43]. In the United States, $40 \%$ of the participants in the smallpox vaccination program were concerned about an adverse event, likely reflecting their focus on the potential risks of vaccination in a context of unclear benefit. At the same time, about $50 \%$ reported that they were not well informed about either the risks or the benefits of vaccination [31].

Communicating effectively about severe side effects that often occur at extremely low rates is particularly challenging [44]. The vividness with which such adverse events are depicted can cause people to overestimate their personal risk [45]. In this situation, stressing the possible benefits from vaccination is quite important, while alleviating concerns about adverse side effects at the same time. Compensation and liability issues should also be well addressed in advance. Furthermore, management of the people with vaccine contraindications should be planned with special attention and caution. In practice, public health professionals and physicians need to explain the details of smallpox vaccination, asking the health conditions of the subjects and explaining the conditions where vaccination should be avoided. When the risk of smallpox infection is quite large, vaccination should, of course be, considered, weighing its potential benefits against its risks. Information should be reworked and translated to a point where it has relevance for each subject within the context of each individual situation and particular level of understanding [46].

When the individual decision on vaccination depends upon the personal calculation of its perceived costs and benefits, independent thinkers can inferably be induced to get vaccinated by the maneuvering of their perception, namely, raising their awareness of bioterrorism threats/ attacks, increasing their expectations of vaccine protection, and reassuring the small incidence rates and mostly mild side effects of smallpox vaccines. This might also be effective to manage the issue of rational exemption, namely, the decision not to get vaccinated after a seemingly rational comparison between the perceived utility and disutility of vaccination [47]. Highlighting the collective importance of vaccination for social protection is also an important method of communication [48].

Whenever possible, to avoid public panic and distrust, it is always advisable not to employ "spin (fearmongering)" communications strategies [49]. People further away (by distance or relationship) from the threat, with the luxury of time to decide their chosen course of action among the possibilities, may actually exercise less reasonable reactions than those who are facing real crisis [50]. When chances are known to be high by the best intelligence that terrorist attacks will occur or have occurred, more people should be, and can be, persuaded to be vaccinated if they are well informed [51]. However, exaggerating the potential for a smallpox incident when it is really slightly greater than hypothetical would result in a backlash in public distrust in subsequent government actions. Honest communication with the public about the uncertainty of different risks (risks of terrorism and vaccine side effects) as well as the pros and cons of precautionary actions is all the more important.

For many, including health care workers, the main source of information about disease, terrorism, and vaccines is the mass media, followed by health centers and professionals $[52,53]$. Both national and local media networks, such as television and radio, are important information sources in the event of a bioterrorist incident [54]. When incidents take place in many locations, however, local communications can be complicated by public exposure to information about other localities and information from the national media. Those who might not have easy access to relevant information, such as the poor, the 
handicapped, and the homeless, need to be targeted with special attention. Foreigners, who could have different cultural norms and attitudes, should also be treated with care when pursuing full coverage of prophylactic vaccination $[55,56]$.

In light of the above discussion, the skillful communication of both risks and benefits of smallpox vaccination is the key to any successful future smallpox vaccination effort. Public health practitioners, as well as physicians, should be prepared to deliver the kinds of information that represent all priorities to the public through effective communication channels [57]. Messages should be deliberately crafted, and media should be carefully selected, in consideration of the social backgrounds of the target groups, especially the independent thinkers. This requires being attentive to the demands of the public for information and actively surveying a community concerning what it still needs to know and how to reach the public [58].

Study limitations and future agenda

With a limited number of simple questions, our study could not fully examine the psycho-behavioral mechanisms by which people make individual decisions on pre-event smallpox vaccination [59]. Research employing in-depth interviews and more detailed questionnaire surveys would advance our understanding. The development of effective communication strategies is also an important agenda for further research. Knowledge on smallpox and vaccination among medical professionals, government officials, and other persons in charge of crisis management should also be assessed [60].

\section{Conclusions}

A substantial number of people indicated some degree of reservation about a future vaccination program against bioterrorism attacks using smallpox. Those in the younger age group, those without past smallpox vaccination, and those who considered the threat of smallpox terrorism to be less serious were more prudent or hesitant. These findings indicate that these people should be targeted with special attention by such programs so that they are well advised/ induced to act promptly for vaccination when required. Contraindications for smallpox vaccination should also be communicated. For that purpose, communication programs should be well planned beforehand to convey both the benefits and the risks of vaccination for these individuals and for society.

Acknowledgments This study was supported by a Health Science Research Grant from the Japan Ministry of Health, Labor and Welfare for the research project titled "Study on the improvements of the health crisis management capacities among local governmental workers (2006-2008)" and a Scientific Grant-in-Aid from the Japan Society for the Promotion of Science for the project titled "Strategic management and communications of health risks (2007-2009)."

\section{References}

1. Tucker JB. Scourge: the once and future threat of smallpox. New York: Atlantic Monthly Press; 2001.

2. Wharton M, Strikas RA, Harpaz R. Recommendations for using smallpox vaccine in a pre-event vaccination program. Morb Mortal Wkly Rep. 2003;52:1-16.

3. Fenner F, Henderson DA, Arita I, Jezek Z, Landnyi ID. Smallpox and its eradication. Geneva: World Health Organization; 1988.

4. Blendon RJ, DesRoches CM, Benson JM, Herrmann MJ, TaylorClark K, Weldon KJ. The public and the smallpox vaccination: a national survey of emergency health care providers. $\mathrm{N}$ Engl $\mathrm{J}$ Med. 2003;348:426-32.

5. Hull HF, Danila R, Ehresmann K. Smallpox and bioterrorism: public health responses. J Lab Clin Med. 2003;142(4):221-8.

6. Mack TM. Smallpox in Europe, 1950-71. J Infect Dis. 1972;125: 161-9.

7. Mack TM, Thomas DB, Khan MM. Epidemiology of smallpox in West Pakistan, II: determinants of intravillage spread other than acquired immunity. Am J Epidemiol. 1972;95:157-68.

8. Breman JG, Henderson DA. Diagnosis and management of smallpox. N Engl J Med. 2002;346:1300-8.

9. Section for Tuberculosis and Infectious Diseases, Ministry of Health, Labor and Welfare, Japan. Guidelines on smallpox vaccination. Tokyo: MHLW; 2004.

10. Cohen LM, McChargue DE, Collins FL. The health psychology handbook: practical issues for the behavioral medicine specialist. Thousand Oaks: Sage Publications; 2003.

11. Hamilton-West K. Factors influencing MMR vaccination decisions following a mumps outbreak on a university campus. Vaccine. 2006;24(24):5183-91.

12. Smedley J, Poole J, Waclawski E, Stevens A, Harrison J, Watson $\mathrm{J}$, et al. Influenza immunization: attitudes and beliefs of UK healthcare workers. Occup Environ Med. 2007;64(4):223-7.

13. Heimberger T, Chang HG, Shaikh M, Crotty L, Morse D, Birkhead G. Knowledge and attitudes of healthcare workers about influenza: why are they not getting vaccinated? Infect Control Hosp Epidemiol. 1995;16(7):412-5.

14. Takayama N, Washio S, Imamura M, Nogushi F, Ozasa K, Ide S. Status of influenza vaccination and factors affecting vaccination in elderly residents. Jpn J Clin Exp Med (Rinsho to Kenkyu). 2008;85(2):129-32.

15. Porter CK, Tribble DR, Halvorson H, Putnam SD, Sanders JW, Riddle MS. Cross-sectional survey of anthrax vaccine coverage and KAP among deployed US military. Hum Vaccin. 2009;5(11): 765-9.

16. Ii M, Ohkusa Y. An empirical research for demand of influenza vaccination. Jpn J Public Health. 2001;48(1):16-27.

17. Watanakunakorn C, Ellis G, Gemmel D. Attitude of healthcare personnel regarding influenza immunization. Infect Control Hosp Epidemiol. 1993;14(1):17-20.

18. Fernandez WG, Oyama L, Mitchell P, Edwards EM, George J, Donovan J, Feldman JA. Attitudes and practices regarding influenza vaccination among emergency department personnel. J Emerg Med. 2009;36(2):201-6.

19. LaVela SL, Smith B, Weaver FM, Legro MW, Goldstein B, Nichol K. Attitudes and practices regarding influenza vaccination among healthcare workers providing services to individuals with 
spinal cord injuries and disorders. Infect Control Hosp Epidemiol. 2004;25:933-40.

20. Winston CA, Wortley PM, Lees KA. Factors associated with vaccination of Medicare beneficiaries in five US communities: results from the Racial and Ethnic Adult Disparities in Immunization Initiative Survey, 2003. J Am Geriatr Soc. 2006; 54:303-10.

21. Timmermans DR, Henneman L, Hirasing RA, van der Wal G. Attitudes and risk perception of parents of different ethnic backgrounds regarding meningococcal $\mathrm{C}$ vaccination. Vaccine. 2005;23(25):3329-35.

22. Oestbye T, Taylor DH, Lee AMM, Greenberg G, van Scoyoc L. Racial differences in influenza vaccination among older Americans, 1996-2000: longitudinal analysis of the Health and Retirement Study (HRS) and the Asset and Health Dynamics Among the Oldest Old (AHEAD) survey. BMC Public Health. 2003;3:41.

23. Lindley MC, Worley PM, Winston CA, Bardenheier BH. The role of attitudes in understanding disparities in adult influenza vaccination. Am J Prev Med. 2006;31(4):281-5.

24. Hayashi Y, Suzuki K, Tonegawa K. Studies of influenza vaccination among elderly nursing home residents. J Jpn Assoc Infect Dis. 2007;81(4):408-13.

25. Rachiotis G, Mouchtouri VA, Kermastinou J, Gourgoulianis K, Hadjichristodoulou C. Low acceptance of vaccination against the 2009 pandemic influenza (H1N1) among healthcare workers in Greece. Euro Surveill. 2010;15(6):1-52.

26. Apisarnthanarak A, Phattanakeitchai P, Warren DK, Fraser VJ. Impact of knowledge and positive attitudes about avian influenza (H5N1 virus infection) on infection control and influenza vaccination practices of Thai healthcare workers. Infect Control Hosp Epidemiol. 2008;29(5):472-4.

27. Katsuno S, Tobusawa C, Tanaka K, Nakajima E, Takahashi H, Saito H. Attitude survey on influenza prepandemic vaccination of hospital staff. Jpn J Environ Infect. 2009;24(3):189-94.

28. O'Reilly FW, Cran GW, Stevens AB. Factors affecting influenza vaccine uptake among health care workers. Occup Med. 2005;55(6):474-9.

29. Horby PW, Williams A, Burgess MA, Wang H. Prevalence and determinants of influenza vaccination in Australians aged 40 years and over: a national survey. Aust N Z J Public Health. 2005;29(1):35-7.

30. Wortley PM, Levy PS, Quick L, Shoemaker TR, Dahlke MA, Evans B, Burke B, Schwartz B. Predictors of smallpox vaccination among healthcare workers and other first responders. Am J Prev Med. 2007;32(6):538-41.

31. Ching P, Tynan WP, Raymond D, Bresnitz E, Craig AS. Hospital recruitment for the smallpox pre-event vaccination program: Experiences from Florida, Nebraska, New Jersey and Tennessee, December, 2002-June, 2003. Public Health Rep. 2004;119: $552-6$.

32. Ault A. US smallpox vaccine programme stalls as volunteers balk. Lancet. 2003;361:1626.

33. Wortley PM, Schwartz B, Levy PS, Quick LM, Evans B, Burke B. Healthcare workers who elected not to receive smallpox vaccination. Am J Prev Med. 2006;30(3):258-65.

34. Yih WK, Lieu TA, Rego VH, O'Brian MA, Shay MA, Yokoe DS. Attitudes of healthcare workers in US hospitals regarding smallpox vaccination. BMC Public Health. 2003;3:20-8.

35. Centers for Disease Control and Prevention. Recommendations for using smallpox vaccine in pre-event vaccination program. Mortal Morb Wkly Rep. 2003;52:1-16.

36. Benin AL, Dembry L, Shapiro ED, Holmboe ES. Reasons physicians accepted or declined smallpox vaccine, February through April, 2003. J Gen Intern Med. 2004;19:85-9.
37. Cameron LD, Leventhal H. The self-regulation of health and illness behavior. London: Routledge; 2003.

38. Danes JE, Hunter JE, Woelfel J. Belief change and accumulated information. In: Hunter JE, Danes JD, Cohen SH, editors. Mathematical models of attitude change. New York: Academic Press; 1985. p. 204-16.

39. Bass SB, Gordon TF, Ruzek SB, Hausman AJ. Mapping perceptions related to acceptance of smallpox vaccination by hospital emergency room personnel. Biosecur Bioterror. 2008;6(2): 179-89.

40. Wright JA, Polack C. Understanding variation in measlesmumps-rubella immunization coverage: a population-based study. Eur J Pub Health. 2005;16(2):137-42.

41. Madjid M, Alfred A, Sahai A, Conyers JL, Casscells SW. Factors contributing to suboptimal vaccination against influenza: results of a nationwide telephone survey of persons with cardiovascular disease. Tex Heart Inst J. 2009;36(6):546-52.

42. Tsutsi Y, Benzion U, Shahrabani S, Din GY. A policy to promote influenza vaccination: a behavioral economic approach. Health Policy. 2010;97:238-49.

43. Coelho FC, Codeco CT. Dynamic modeling of vaccinating behavior as a function of individual beliefs. PLoS Comput Biol. 2009;5(7):e1000425.

44. Lipkus IM, Hollands JG. The visual communication of risk. J Natl Cancer Inst Monogr. 1999;25:149-63.

45. Paling J. Strategies to help patients understand risks. Br Med J. 2003;327:745-8.

46. McMurray R, Cheater FM, Weighall A, Nelson C, Schweiger M, Mukherjee S. Managing controversy through consultation: a qualitative study of communication and trust around MMR vaccination decisions. Br J Gen Pract. 2004;54:520-5.

47. Manfredi P, Posta PD, d'Onofrio A, Salineli E, Centrone F, Meo C, Poletti P. Optimal vaccination choice, vaccination games, and rational exemption: an appraisal. Vaccine. 2010;28:98-109.

48. Perisic A, Bauch CT. Social contact networks and disease eradicability under voluntary vaccination. PLoS Comput Biol. 2009;5(2):e1000280.

49. Keselman A, Slaughter L, Patel VL. Toward a framework for understanding lay public's comprehension of disaster and bioterrorism information. J Biomed Inform. 2005;38:331-44.

50. Sandman PM. Responding to community outrage: strategies for effective risk communication. Fairfax: American Industrial Hygiene Association; 1993.

51. Selgelid MJ. Bioterrorism and smallpox planning: information and voluntary vaccination. J Med Ethics. 2004;30:558-60.

52. Madar R, Repkova L, Baska T, Straka S. Influenza vaccination: knowledge, attitudes, cover rate-can they be improved? Bratislavske Lekarske Listy. 2003;104(7-8):232-5.

53. Dannetun E, Tegnell A, Hermansson G, Glesecke J. Parents' reported reasons for avoiding MMR vaccination: a telephone survey. Scand J Prim Health Care. 2005;23(3):149-53.

54. Pollard WE. Public perceptions of information sources concerning bioterrorism before and after anthrax attacks: an analysis of national survey data. J Health Commun. 2003;8:93-103.

55. United States Government Accountability Office. Bioterrorism: Public health response to anthrax incidents of 2001. Report to the Honorable Bill Frist, Majority Leader, US Senate. Washington DC: GAO; 2003.

56. McKenna VB, Gunn JE, Auerbach J, Brinsfield KH, Dyer KS, Barry MA. Local collaborations: development and implementation of Boston's bioterrorism surveillance system. J Public Health Manage Pract. 2003;9(5):384-93.

57. Donna PG, Ardene RV, Sarla S. Influenza vaccination by registered nurses: a personal decision. Can J Infect Control. 2009; 24(1):18-26. 
58. Schoch-Spana M. Educating, informing, and mobilizing the public. In: Levy BS, Sidel VW, editors. Terrorism and public health: a balanced approach to strengthening systems and protecting people. Oxford University Press, Oxford; 2003. p. 118-35.

59. Kaltman S, Tractenberg RE, Taylor K, Green BL. The smallpox vaccine: a multidimensional model of choice. Biosecur Bioterror. 2006;4(1):64-73
60. Dellavalle RP, Heilig LF, Francis SO, Johnson KR, Hester EJ, McNealy KM. What dermatologists do not know about smallpox vaccination: results from a worldwide electronic survey. J Invest Dermatol. 2006;126:986-9. 